\title{
A GESTÃO DE RISCOS E SEU PROTAGONISMO NO PROCESSO DECISÓRIO DA MARINHA DO BRASIL
}

\author{
Thiago Martins Amorim \\ Escola de Guerra Naval/Marinha do Brasil \\ Endereço Corporativo \\ thiago.martins@marinha.mil.br \\ Thiago Silva e Souza \\ Escola de Guerra Naval/Marinha do Brasil \\ Endereço Corporativo \\ thiago.souza@marinha.mil.br
}

\begin{abstract}
RESUMO
O protagonismo da gestão de riscos no processo de tomada de decisão é o objeto dessa pesquisa que, por sua importância e atualidade, especialmente após a instituição da Política de Governança Pública, no âmbito federal, sugere que o Estado se reinvente, deixando o papel de financiador de políticas públicas e passando a articulador de parcerias em função do interesse social. A partir de um estudo exploratório-descritivo, um survey de análise da maturidade de Business Process Management (BPM), buscou-se a transposição de conceitos de gestão estratégica e governança corporativa ao ambiente público, devidamente criticados e contextualizados ao apresentar a estrutura da gestão de risco e sua importância no aprimoramento do controle interno de organizações da Marinha do Brasil.
\end{abstract}

Palavra-chave: Governança Pública; Gestão Pública; Gestão de Riscos; Controle Interno; Marinha do Brasil.

\begin{abstract}
The risk management protagonism in the decision-making process is the research object which, due to its importance and timeliness, especially after the establishment of the Federal Public Governance Policy, suggests that the State reinvents itself, leaving the role of financier public policies and becoming the partnerships articulator according to the social interest. From an exploratory-descriptive study, a Business Process Management (BPM) maturity analysis survey, sought to transpose concepts of strategic management and corporate governance into the public environment, duly criticized and contextualized by presenting the risk management structure and its importance in improving the internal control of Brazilian Navy organizations.
\end{abstract}

Keywords: Public Governance; Public Administration; Risk Management; Internal Control; Brazilian Navy.

\section{Como Citar:}


AMORIM, Thiago Martins; SOUZA, Thiago Silva e. A gestão de riscos e seu protagonismo no processo decisório da Marinha do Brasil. In: SIMPÓSIO DE PESQUISA OPERACIONAL E LOGÍSTICA DA MARINHA, 19., 2019, Rio de Janeiro, RJ. Anais [...]. Rio de Janeiro: Centro de Análises de Sistemas Navais, 2019.

\section{INTRODUÇÃO}

Num mundo cada vez mais complexo, investidores e sociedade exigem dos agentes dos setores público e privado boas práticas na gestão de seus recursos, a fim de mitigar os crescentes e diversificados riscos que surgem no ambiente corporativo que, via de regra, podem impactar, negativamente, sua capacidade de alcançar objetivos ou perceber novas oportunidades para a inovação de seus negócios.

Especificamente para o setor público, esses agentes ainda precisam atentar para constantes mudanças no arcabouço jurídico nacional, resultando em considerável insegurança jurídica. Ademais, o fator ética na gestão pública tem ganho destaque nos últimos anos, como pilar de governabilidade e legítima administração dos rumos da sociedade, suportadas por aspectos como liderança, integridade, responsabilidade, compromisso, transparência e accountability, mitigando assim os riscos organizacionais e visando à melhoria dos serviços prestados ao seu principal cliente: o cidadão.

O que se observa, então, é que desde a redemocratização, o Estado brasileiro vem se reinventando, na constante busca pelo bem-estar social e econômico de seus cidadãos. A atribuição constitucional de uma série de tarefas nos campos político, econômico e social depende da boa gestão do erário, uma vez que não se cria receita pública, mas sim, administra-se a riqueza do povo.

Aprimorar a qualidade do gasto público e fomentar a eficiência na elaboração e execução de políticas públicas se tornou, especialmente nos últimos anos, um crescente desafio. A necessidade da manutenção do equilíbrio fiscal, da estabilidade monetária e da racionalização dos gastos públicos imputam ao administrador a difícil tarefa de legitimar suas atividades, diuturnamente questionada quanto a coerência de atos e fatos resultantes de suas decisões, em especial quando relacionados a preteridos investimentos em setores estratégicos como educação, saúde e segurança pública.

Ademais, o Estado, ao perder sua capacidade de atuar como financiador de setores fundamentais da economia, com destaque à infraestrutura, por sua intensa capacidade de gerar emprego e renda, novamente tem que se readaptar, passando a assumir o papel de articulador de interesses sociais, em constantes arenas políticas, com diferentes partes interessadas.

O cenário precário das contas públicas brasileiras, especialmente a partir do segundo semestre de 2013, exige um encadeamento lógico dos instrumentos que compõem o planejamento nacional.

A recém instituída Política de Governança Pública objetiva contribuir para que "as políticas públicas sejam formuladas e implementadas a partir da melhoria do ambiente institucional em cada órgão e em cada entidade da administração pública federal e da coordenação, mas efetiva desse processo” (BRASIL, 2018, p.82).

Reconhecendo como de fundamental importância a análise contextual para o fomento da manutenção do processo decisório orientado por evidências, assim como para a eficaz definição da atuação estatal de qualidade, a criação desse arcabouço institucional 
capacita o direcionamento, a avaliação e o monitoramento sustentável da gestão, permitindo um caminhar gradual da administração pública no sentido de incorporar e aplicar as melhores práticas de governança.

No âmbito da Marinha do Brasil (MB), os controles internos, a governança e a gestão de riscos foram implementados no nível organizacional, no denominado Planejamento Estratégico Organizacional (PEO), assim como constante dos regimentos internos de todas Organizações Militares (OM). Logo, tem-se como problema de pesquisa: Como a Gestão de Risco tem contribuído para o processo de tomada de decisão nas OM da $\mathrm{MB}$ ?

Para tal, optou-se por organizações pertencentes ao Sistema de Abastecimento da Marinha do Brasil (SAbM) que, por definição, tem a finalidade de promover, manter e controlar o provimento do material necessário à manutenção da Força e demais Órgãos Navais em condição de plena eficiência.

Ao apresentar o diagnóstico de implementação de controles internos fundamentados na gestão de riscos, privilegiando ações estratégicas de prevenção antes de processos sancionadores, busca-se nesse artigo reconhecer a natureza dinâmica da administração pública, assim como privilegiar a reflexão sobre a adaptabilidade de modelos de gestão às mudanças de contexto.

Enfim, acredita-se que o estudo contribuirá para a reflexão do conceito de integridade pública, ou seja, da viabilidade do alinhamento consistente e à adesão de valores, princípios e normas éticas comuns para sustentar e priorizar o interesse público, no difícil equilíbrio entre punir e preservar o espaço para a inovação do gestor, assim não se transformando em uma estrutura inibidora da boa gestão pública.

\section{REVISÃO DA LITERATURA}

A contemporaneidade da temática pode ser percebida na crescente produção acadêmica, reflexões organizacionais e normatização das práticas voltadas à integração do controle interno e da governança na atividade estatal, com o protagonismo da gestão de risco nesses fóruns de discussão, o que demonstram a importância da revisão literária dos principais aspectos envolvidos no objeto deste artigo.

\subsection{CONTROLE NA ADMINISTRAÇÃO PÚBLICA}

A Carta Magna trouxe ao cidadão uma ampla previsão de direitos, assim como uma nova estrutura de Estado, a fim de poder ser mais permeável às demandas dessa nova sociedade. Com isso, a participação da sociedade nas decisões dos rumos do país não apenas se tornou possível, mas necessária ao bom funcionamento do aparato público.

Da literatura, podemos destacar a existência de dois principais tipos de controle: (i) aquele exercido pela própria Administração Pública, que é chamado de controle institucional; e (ii) o exercido pela sociedade, denominado controle social.

Especificamente quanto ao controle institucional, depreende-se ser aquele em que a própria Administração Pública exerce sobre sua atividade governamental, tendo como pano de fundo a própria Constituição Federal de 1988, onde em seu art. 70 dispõe que:

\footnotetext{
“A fiscalização contábil, financeira, orçamentária, operacional e patrimonial da União e das entidades da administração direta e indireta, quanto à legalidade, legitimidade, economicidade, aplicação das subvenções e renúncia de receitas, será exercida pelo Congresso Nacional, mediante controle externo, e pelo sistema de controle interno de cada Poder.” (art. 70, CF/88)
} 
Sendo assim, observa-se que este controle institucional ainda se divide em outros tipos, a saber: o controle interno e o controle externo. Logo, trazendo a doutrina de Meirelles (2016), enquanto o controle externo é realizado por órgão estranho à Administração responsável pelo ato controlado, o controle interno decorre de órgão integrante da própria estrutura do órgão controlado, isto é, está inserido no Sistema de Controle Interno de cada Poder.

O arcabouço normativo tem favorecido o cidadão a assumir o seu papel de protagonista da democracia e a exigir das instituições públicas a adoção de uma postura mais confiável, transparente, justa e com responsabilidade. Por meio da participação na gestão pública, os cidadãos podem influenciar seus representantes quando do processo de tomada de decisão, orientando o administrador público para que adote medidas que realmente atendam ao interesse público, assim como podem exercer controle sobre a ação do Estado, exigindo desse mesmo gestor que preste o melhor serviço à sociedade, de forma eficiente e transparente, por meio de avaliações e acesso à informação, como nas prestações de contas.

Na concepção de Machado (2012), há uma integração entre os ambientes de controle no qual o controle institucional atua como fonte alimentadora e promovedora de uma efetiva participação social. Enquanto o controle interno intervém sob o enfoque de mitigar os riscos organizacionais para o alcance dos resultados institucionais, o controle externo procede a validação dos atos, por meio de técnicas de auditoria e da adequação dos controles internos existentes.

\subsection{GESTÃO DE RISCOS}

No conceito integrado do COSO (Committee of Sponsoring Organizations or the Treadway Commission), riscos são incertezas inerentes a um conjunto de possíveis consequências (ganhos e perdas) que resultam de decisões tomadas pela organização e o gerenciamento de riscos é um mecanismo que produz a estabilidade organizacional, por meio da identificação, priorização, mitigação e mensuração da implicação de cada decisão.

Em 2004, publicou-se o Enterprise Risk Management - integrated framework (COSO-ERM), modelo de referência que tem o gerenciamento de riscos corporativos como foco de análise, representado por uma matriz tridimensional, que busca demonstrar a integração dos elementos que compõem o cubo. (COSO, 1992; 2004).

Figura $n^{\circ}$ 1: Modelo COSO-ERM.

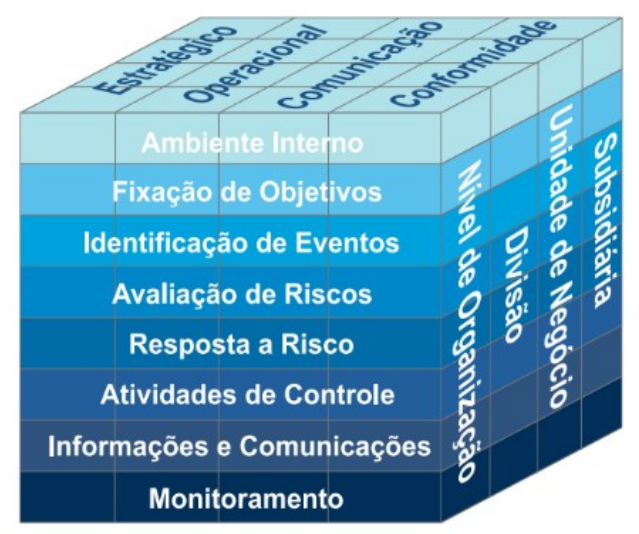

Fonte: COSO (2004)

Existe um relacionamento direto entre os objetivos que uma organização se empenha em alcançar e os componentes do gerenciamento de riscos corporativos, que representam o que é necessário para o seu alcance e a estrutura organizacional da entidade. 
Os oito componentes são inter-relacionados e integram o modo pelo qual a administração gerencia a organização. Além disso, servem de critério para determinar se o gerenciamento de riscos é eficaz ou não.

O gerenciamento de riscos corporativos está sujeito a limitações, por proporcionar segurança razoável, mas não absoluta. Essas limitações incluem o fato de que o julgamento humano, no processo decisório, pode ser falho. Além disso, os controles podem ser anulados por conluio entre duas ou mais pessoas.

Os papéis e as responsabilidades essenciais de gerenciamento de riscos e controles são entendidos com mais clareza na abordagem das Três Linhas de Defesa, que é aplicável a qualquer organização, conforme ilustração baseada na Declaração de posicionamento do Institute of Internal Auditors (IIA, 2013).

Quadro ${ }^{\circ}$ 1: As Três Linhas de Defesa.

\begin{tabular}{|l|l|l|}
\hline \multicolumn{1}{|c|}{$\mathbf{1}^{\mathbf{a}}$ Linha de Defesa } & \multicolumn{1}{c|}{$\mathbf{2}^{\mathbf{a}}$ Linha de Defesa } & \multicolumn{1}{c|}{$\mathbf{3}^{\mathbf{a}}$ Linha de Defesa } \\
\hline $\begin{array}{l}\text { Funções que gerenciam e } \\
\text { têm propriedade de riscos. }\end{array}$ & Funções que supervisionam riscos. & $\begin{array}{l}\text { Funções que fornecem avaliações } \\
\text { independentes. }\end{array}$ \\
\hline $\begin{array}{l}\text { - Gerência operacional. } \\
\text { - Procedimentos diários de de compliance ou conformidade). } \\
\text { controles. }\end{array}$ & $\begin{array}{l}\text {-Monitorar riscos e controles (func̃es } \\
\text { de } \\
\text {-Independência limitada. } \\
\text {-Reporta primariamente à gerência. }\end{array}$ & $\begin{array}{l}\text { - Auditoria Interna (Avaliação de Ris- } \\
\text { cos, Controles e Governança). } \\
\text { - Maior independência. } \\
\text { - Reporta ao órgão de governança. }\end{array}$ \\
\hline
\end{tabular}
Fonte: Elaboração própria.

Os órgãos de governança e a alta administração não estão nas três linhas de defesa, mas exercem papéis essenciais para instituir e assegurar o bom funcionamento dessas linhas no processo de gerenciamento de riscos e controles da organização. Por outro lado, os órgãos de controle externo, reguladores e auditores externos são linhas adicionais de defesa, fora da estrutura da organização, que fornecem avaliações tanto às partes interessadas externas da organização, como ao próprio órgão de governança e à alta administração da entidade.

Figura $n^{\circ}$ 2: Relação entre as linhas de defesa e o TCU

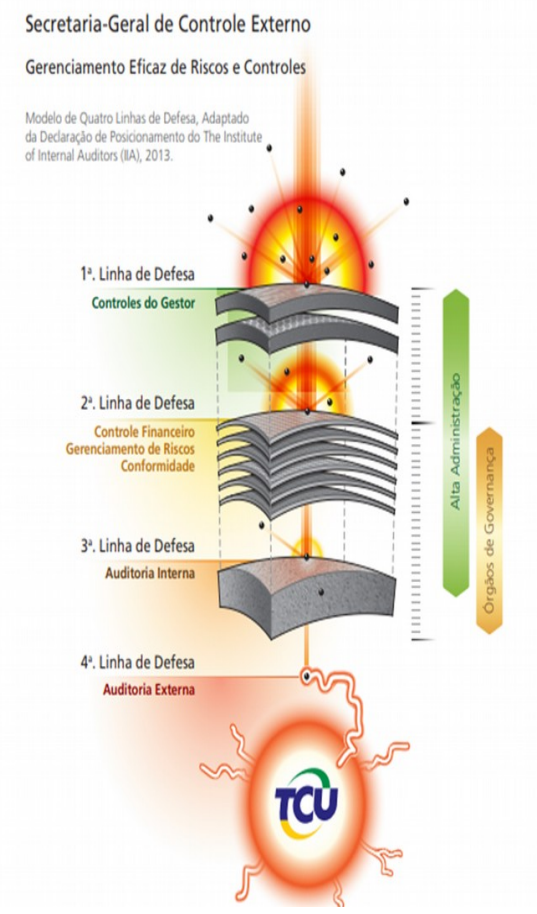

Fonte: TCU (2016, p.14) 
De forma complementar, a figura anterior reforça a citada orientação do IIA quanto as 3 linhas de defesa, sob a ótica da Secretaria-Geral de Controle Externo da Corte de Contas do país, ou seja, como o TCU entende os mecanismos de gerenciamento de riscos e controles que devem ser exercidos antes de sua efetiva atuação como controle externo nacional.

Ademais, importante ressaltar que controle e integridade não são sinônimos, mas sim conceitos complementares, podendo se tornar contraproducentes quando utilizados de forma excessiva, ou seja, ao invés de privilegiar atividades de prevenção, mitigando possíveis vulnerabilidades e se preparando para evitar reincidências, priorizam a cultura da punição.

\subsection{POLÍTICA DE GOVERNANÇA PÚBLICA}

Na percepção de Harrison (1998), há que se ressaltar uma singular e complementar diferença entre os conceitos de gestão e governança:

(...) há uma distinção entre gestão e governança, uma vez que o propósito desta não é apenas executar o negócio da organização, mas projetar uma diferença global para a organização, ou seja, uma gestão estratégica capaz de supervisionar e controlar as ações executivas de seus gestores e satisfazer as expectativas legítimas pela prestação de contas e regulação por parte das partes interessadas. (HARRISON, 1998, p.142)

O termo gestão estratégica ganha destaque a partir dos anos 50 , resultado do desenvolvimento de modelos teóricos e práticos que buscavam dar sustentabilidade ao processo de tomada de decisão do gestor, na busca pela eficiência operacional (PORTER, 1996; MINTZBERG, AHLSTRAND \& LAMPEL, 1998).

Para Rodrigues, Tavares e Araújo (2012, p.99):

Há muito que o conceito de governança deixou de ser mera tomada de decisão e implementação de estrutura da administração pública, relativamente à produção de bens e serviços públicos. Atualmente, têm-se discutido o conceito de boa governança, que compreende a noção de gerir uma realidade complexa através de uma combinação adequada de mecanismos de governança.

Assim sendo, no contexto da administração pública brasileira, destaque ao entendimento do Tribunal de Contas da União (TCU, 2014, p.26), segundo o qual governança compreende "mecanismos de liderança, estratégia e controle postos em prática para avaliar, direcionar e monitorar a atuação da gestão, com vistas à condução de políticas públicas e à prestação de serviços de interesse da sociedade”. Ou seja, governança e gestão no setor público são funções complementares.

Figura nº 3: Relação entre Governança e Gestão
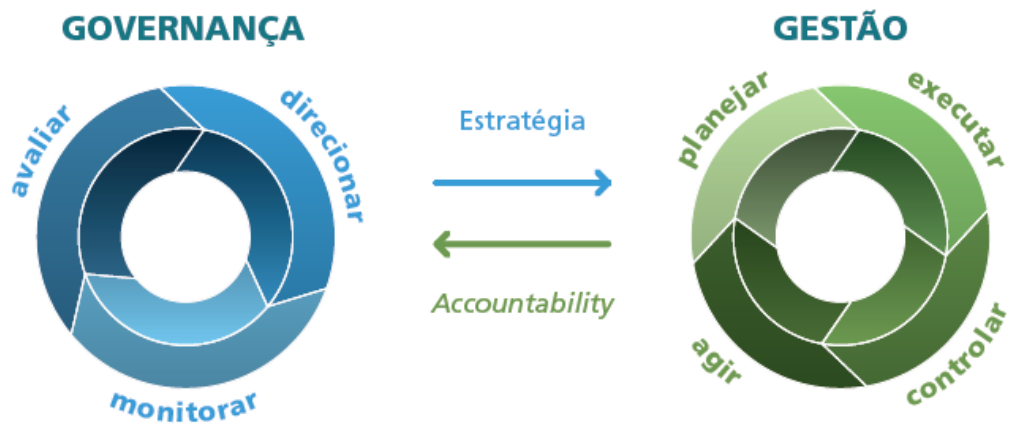

Fonte: TCU (2014, p.32) 
Tendo por base os preceitos sintetizados do art. $3^{\circ}$ da Carta Magna de: construir uma sociedade livre, justa e igualitária; garantir o desenvolvimento nacional; erradicar a pobreza e reduzir a desigualdade sociais e regionais; e promover o bem de todos, sem quaisquer formas de discriminação, foi instituída a Política de Governança da Administração Pública Federal, por meio do Decreto n ${ }^{\circ}$ 9.203/2017.

Valoroso colaborador na elaboração do Guia da Política de Governança Pública (BRASIL, 2018), o professor Guy Peters orienta que dois elementos são cruciais na construção de uma boa governança:

a) O conjunto de instituições que pode moldar a maneira como as decisões são tomadas, assim como fornecer legitimidade para as ações implementadas pelo setor público; e

b) As pessoas que trabalham no setor público, respaldadas pela burocracia que, apesar das inúmeras críticas, possibilita a implementação de políticas públicas ao fornecer assessoria a líderes políticos e memória institucionalizada das políticas e da administração.

Nesse contexto, um dos desafios da boa governança pública é determinar quanto risco aceitar quando do processo de tomada de decisão, buscando o equilíbrio responsável em prol do melhor valor para o cidadão e demais partes interessadas. Assim, resta destaque a forte inter-relação entre os conceitos de governança e gestão de risco, e esta com a precípua existência de controles internos adequados. (INTOSAI, 2001; MACHADO, 2012).

A Instrução Normativa Conjunta CGU/MP n 001/2016 define medidas para a sistematização de práticas relacionadas à gestão de riscos, aos controles internos e à governança. Assim, geridos de forma integrada, busca-se estabelecer um ambiente que respeite não apenas os valores, interesses e expectativas das instituições e agentes públicos, mas de todas as demais partes interessadas, tendo o cidadão e a sociedade como principais vetores desse processo.

Entretanto, não basta evidenciar expectativas da sociedade, tampouco destacar a importância de políticas públicas em áreas ditas essenciais, sem antes ponderar seus custos, potenciais benefícios, formas de execução e monitoramento de resultados, a fim de aprimorar o processo decisório de alocação de recursos públicos, assim como a qualidade do gasto, em prol da melhor prestação de serviços ao cidadão.

O Novo Regime Fiscal, instituído pela Emenda Constitucional n ${ }^{\circ}$ 95/2016 trouxe novos desafios ao Estado no que tange à gestão financeira e orçamentária. Diante de um cenário de total desequilíbrio fiscal, especialmente observado a partir do segundo semestre de 2013, quando as despesas ditas primárias superam, pela primeira vez, as receitas da União, o país convive, ano após ano, na situação deficitária em suas contas públicas.

Assim, observa-se como promissor instrumento de incentivo ao alcance do efetivo retorno econômico e social ao menor sacrifício possível da sociedade, os 6 princípios previstos na Política de Governança Pública (BRASIL, 2018, p. 84-85), independentemente do ciclo econômico vivenciado pela país:

a) Capacidade de resposta: representa a competência de uma instituição pública de atender de forma eficiente e eficaz as necessidades dos cidadãos;

b) Integridade: refere-se ao alinhamento consistente e à adesão de valores, princípios e normas éticas comuns para sustentar e priorizar o interesse público sobre os interesses privados no setor público; 
c) Confiabilidade: capacidade das instituições de minimizar as incertezas para os cidadãos nos ambientes econômico, social e político;

d) Melhoria regulatória: representa o desenvolvimento e a avaliação de políticas e de atos normativos em um processo transparente, baseado em evidências e orientado pela visão de cidadãos e partes diretamente interessadas;

e) Prestação de contas e responsabilidade: também conhecido pela expressão accountability, representa a vinculação necessária entre decisões, condutas e competências e seus respectivos responsáveis; e

f) Transparência: compromisso da administração pública com a divulgação das suas atividades, prestando informações confiáveis, relevantes e tempestivas à sociedade.

Especificamente ao conceito de integridade, o uso de controles internos para a manutenção dos riscos em níveis adequados e aceitáveis, a partir da existência de um sistema efetivo de gestão de riscos, busca privilegiar ações estratégicas da organização, a fim de se prevenir à necessidade de processos sancionadores e, consequentemente, inibidores ao espírito público da busca de soluções inovadoras.

\section{ESTUDO EMPÍRICO}

O estudo científico tem por objetivo a produção de conhecimento, sendo este nunca definitivo; erros e correlações interpretativas da ligação entre teoria e análise empírica fazem parte do processo de investigação, em especial quando há o predomínio do paradigma quantitativo sobre o qualitativo (CAMÕES, 2012; MOREIRA, 2007).

\subsection{METODOLOGIA}

Instrumentalizada por estudo exploratório-descritivo, baseado em survey, adaptado do framework de maturidade Business Process Management (BPM) do EloGroup (2015), trata-se de uma estratégia recomendada para situações onde há pouco controle sobre os acontecimentos e o foco se encontra em fenômenos contemporâneos, inseridos em algum contexto da vida real, podendo ser qualitativamente complementado por pesquisas bibliográficas e documentais em suas lacunas de análise (YIN, 2015).

Quadro ${ }^{\circ}{ }^{3}$ : Características dos Estágios de Maturidade em Gestão de Riscos.

\begin{tabular}{|c|c|l|}
\hline Nível & Estágio & \multicolumn{1}{|c|}{ Descrição da Gestão de Riscos da Organização } \\
\hline 1 & Ingênuo & Nenhuma abordagem formal desenvolvida para a Gestão de Risco. \\
\hline 2 & Consciente & Abordagem para a Gestão de Riscos dispersa em “silos”. \\
\hline 3 & Definido & $\begin{array}{l}\text { Estratégias e políticas implementadas e comunicadas. Apetite por } \\
\text { riscos definido. }\end{array}$ \\
\hline 4 & Gerenciado & $\begin{array}{l}\text { Abordagem corporativa para a Gestão de Riscos desenvolvida e } \\
\text { comunicada. }\end{array}$ \\
\hline 5 & Otimizado & $\begin{array}{l}\text { Gestão de Riscos e controles internos atuam de forma integrada à } \\
\text { Governança. }\end{array}$ \\
\hline
\end{tabular}

Fonte: Adaptado de EloGroup/BPM (2015).

Para Freitas et al. (2000, p. 107), privilegia-se a quantificação e as relações de causalidade, assentadas em método estatístico básico, conseguindo-se caracterizar a amostra, 
coletar, tratar e apresentar dados em função do "custo, tempo e forma, para que venha a garantir uma taxa de resposta aceitável ao estudo”.

Com base na revisão teórica, avaliar o estágio de implementação da política de gestão de riscos na Marinha do Brasil alicerça uma reflexão sobre a sustentabilidade das decisões tomadas no setor público, uma vez que a boa governança requer coerência e legitimidade às ações de parceria com o setor privado.

\subsection{CONTEXTUALIZAÇÃO}

A investigação limitou sua amostra às organizações militares pertencentes à estrutura do Sistema de Abastecimento da Marinha do Brasil (SAbM). Composto por órgãos, processos e recursos interligados e interdependentes, tem o propósito de promover, manter e controlar o fornecimento de material necessário à manutenção dos meios navais, aeronavais e de fuzileiros navais, sediados ou em trânsito nas áreas de jurisdição dos Comandos Distritais, em todo o território nacional.

Figura no 4: Área de jurisdição dos Comandos de Distrito Naval

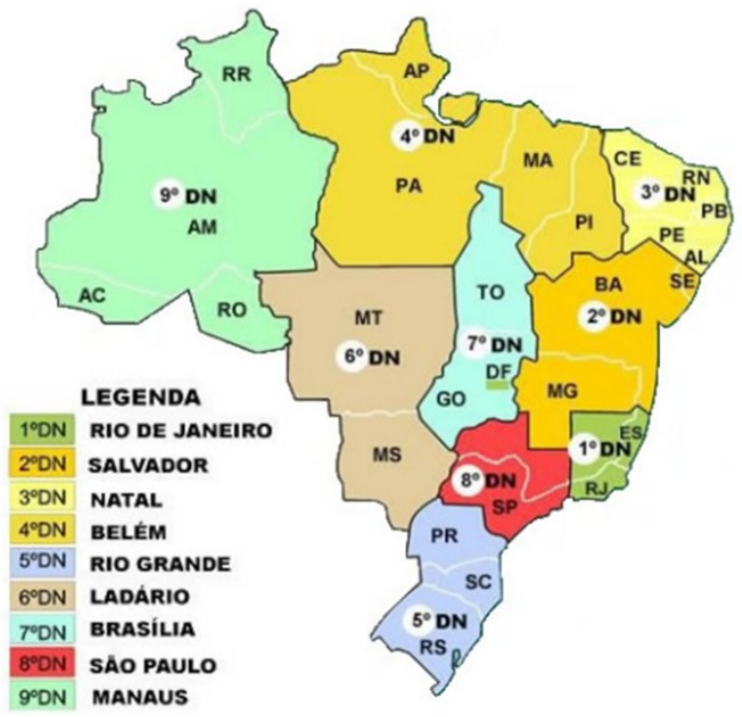

Fonte: Marinha do Brasil

Nesse contexto, os denominados Centros de Intendência, pertencentes à estrutura organizacional da Secretaria-Geral da Marinha (SGM) são estabelecimentos regionais, com autonomia administrativa e função primeira de apoio logístico, com atividades afetas ao abastecimento, obtenção e pagamento de pessoal, assim como a centralização da execução orçamentária e financeira das organizações militares de sua área de jurisdição.

Quanto à temática Gestão de Riscos, tem-se como conceito institucional:

Consiste na aplicação de princípios e processos para identificação e avaliação de riscos os quais as organizações estão expostas em suas atividades. Esse gerenciamento aborda os processos de planejamento, identificação, análise, planejamento de respostas e controle de riscos de uma organização. Seus objetivos são aumentar a probabilidade e o impacto dos eventos positivos e reduzir ou minimizar os dos negativos. (BRASIL, 2015, p.11-1).

Ademais, a Política de Gestão de Riscos (BRASIL, 2017) define a estrutura de gestão e os critérios para análise que possam comprometer o alcance dos objetivos estratégicos da instituição. 
Enquanto as decisões são de competência do Comandante da Marinha, cabe ao Estado-Maior da Armada a responsabilidade pelo planejamento, coordenação, fiscalização e controle das atividades referentes à Gestão de Riscos, apoiado por:

a) Comissão Permanente de Gestão de Riscos;

b) Órgão de Auditoria Interna;

c) Núcleo de Comunicação de Riscos;

d) Subcomissões Permanentes de Gestão de Riscos; e

e) Órgãos de Execução dos Controles de Riscos.

Vale destacar o papel do Centro de Controle Interno da Marinha (CCIMAR) como responsável pelo processo de Auditoria Interna, órgão de assessoria permanente, destinado a auxiliar a MB a realizar seus objetivos, a partir da aplicação de uma abordagem sistemática e disciplinada para avaliar e melhorar a eficácia dos processos de gerenciamento de riscos, de controles internos, de integridade e de governança. Nesse contexto, considerando a estrutura da gestão de riscos, a auditoria interna contribui para o aprimoramento dos controles internos das organizações, para que possam mitigar os principais riscos que impeçam que a $\mathrm{MB}$ alcance seus objetivos estratégicos.

Figura nº 5: Estrutura da Gestão de Riscos da Marinha do Brasil (MB)

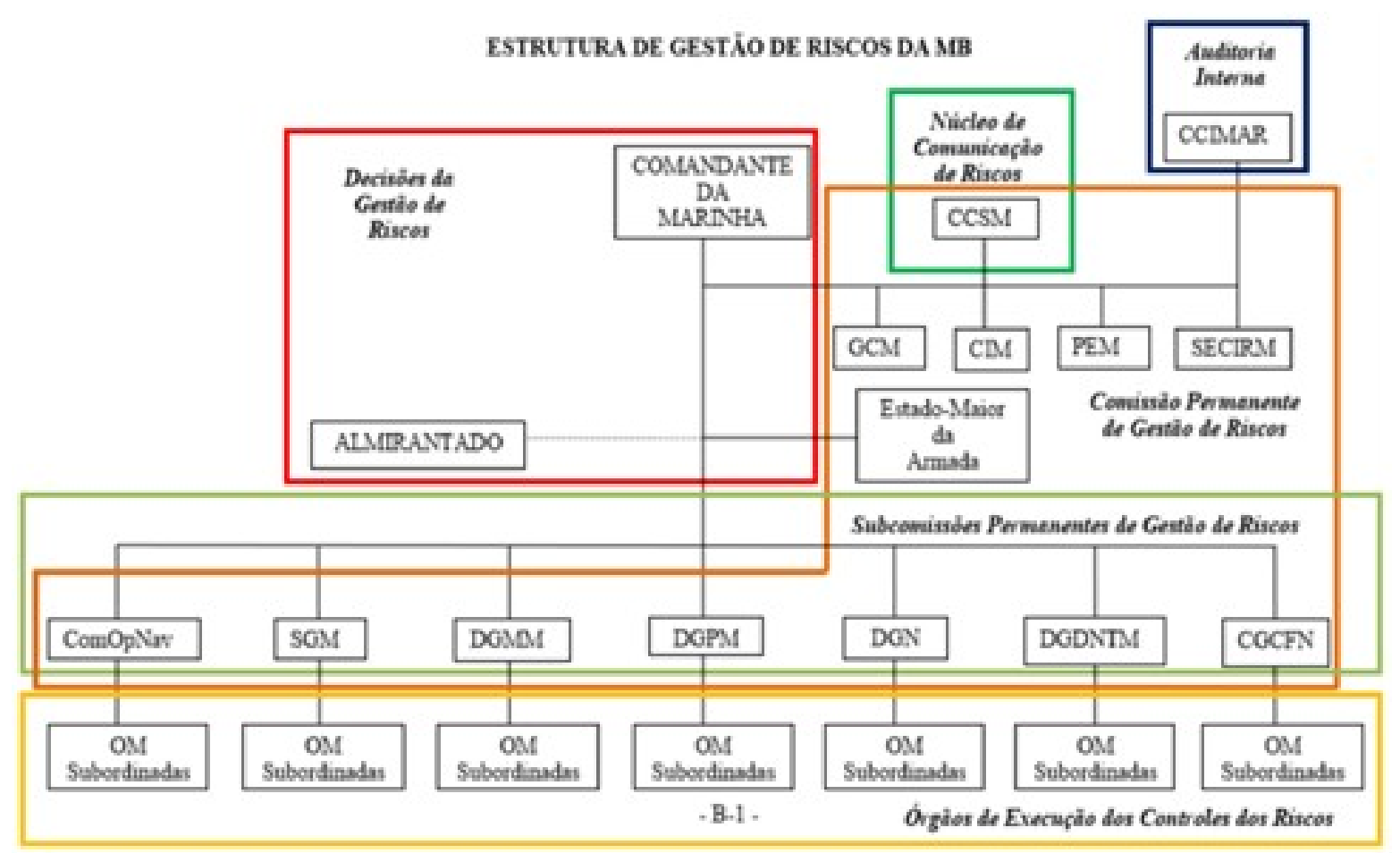

Fonte: BRASIL (2017)

Outro órgão de assessoria permanente, o Centro de Comunicação Social da Marinha (CCSM) é o responsável pela gestão do processo de Comunicação de Riscos, destinado a executar o processo de comunicação e consulta sobre os riscos da MB.

A Gestão de Riscos é um processo em cadeia que interage com todos os níveis da MB, porém é importante ressaltar que cada organização militar, como órgão de execução dos controles dos riscos, deve estabelecer seu Plano de Gestão de Riscos, identificando e avaliando a estrutura organizacional, o contexto de atuação, as características 
e as atividades-fim, assim como ser acompanhado, mensalmente, pelo Conselho de Gestão ou Comissão Interna de Gestão de Risco.

Além disso, destaca-se a necessidade da promoção à cultura de riscos, no intuito de divulgar a importância da informação, comunicação e monitoramento do gerenciamento de riscos, integrado aos controles internos e ao modelo de gestão da OM.

Por fim, em que pese a revogação do Programa Nacional de Gestão Pública e Desburocratização - Gespública (Decreto $n^{0}$ 9.094/2017), com atribuição incorporada ao criado Conselho Nacional para a Desburocratização - Brasil Eficiente, a Marinha mantém os fundamentos ${ }^{1}$, objetivos e instrumentos anteriormente instituídos, com a finalidade de melhoria contínua de sua gestão. O denominado Programa Netuno, criado em 2007, centra suas atividades na dinâmica de autoavaliação, estruturada em uma lista de verificação aplicada em todas as organizações, quando do período denominado Inspeção Administrativo-Militar (IAM).

Observa-se um movimento que incorpora o aprendizado do Gespública e amplifica o potencial de ganhos para a sociedade, pois o Programa Netuno já está consolidado como modelo de gestão na Marinha do Brasil, com mais de uma década de existência, comprovando o alto grau de desempenho institucional de suas organizações militares.

Nesse diapasão, Machado (2012) afirma que orientar a gestão por resultados significa dotar as estruturas, os processos e a administração dos recursos disponíveis, de um modelo de gestão que possibilite uma integração consistente entre as políticas de governo e os resultados planejados de cada um dos órgãos que compõem as esferas do governo.

Figura $^{\circ}$ 6: Modelo de Excelência em Gestão da MB - Programa Netuno

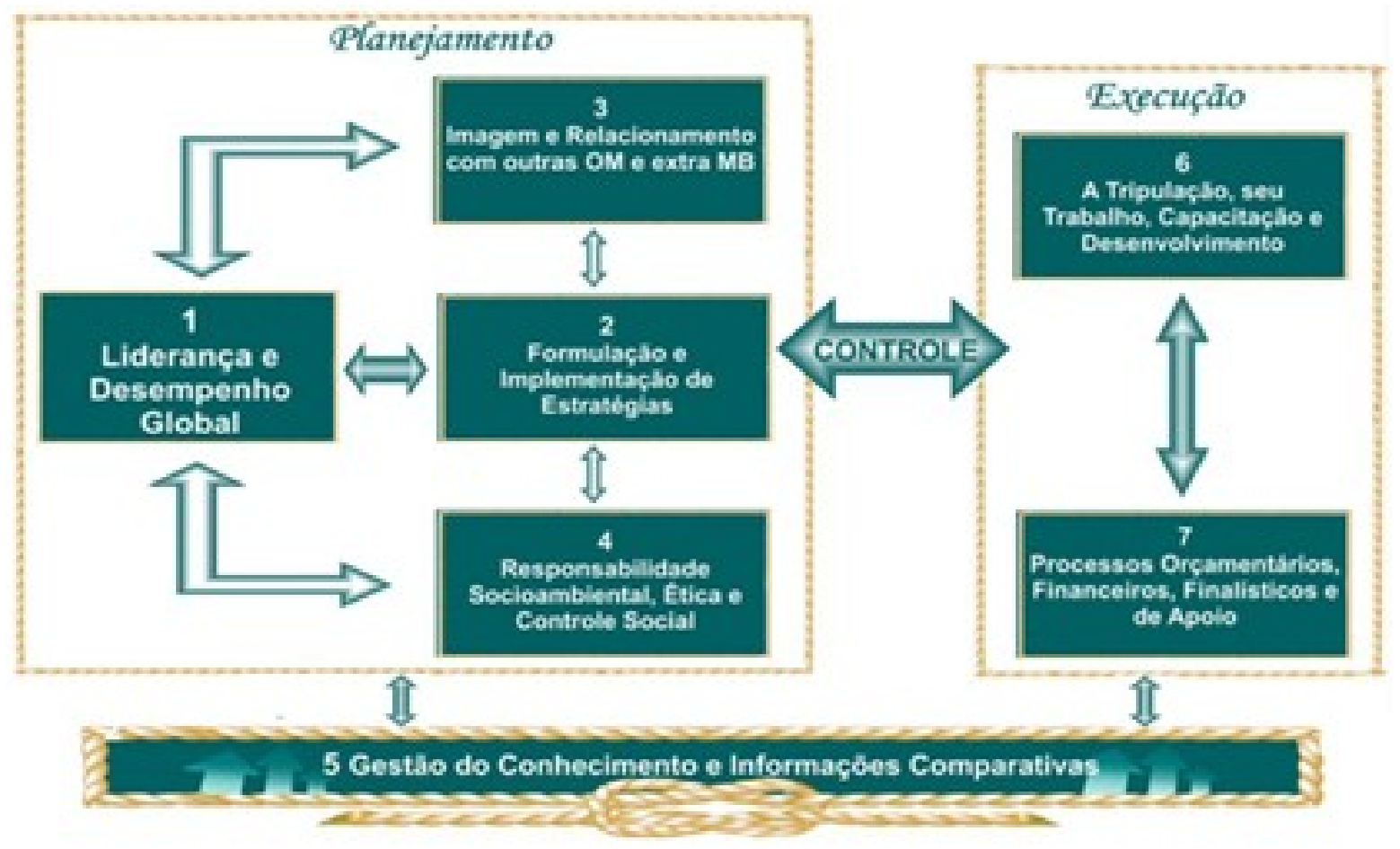

Fonte: BRASIL (2015)

\footnotetext{
${ }^{1}$ Fundamentos da GesPública: (1) pensamento sistêmico; (2) aprendizado organizacional; (3) cultura de inovação; (4) liderança e constância de propósitos; (5) orientação por processos e informações; (6) visão de futuro; (7) geração de valor; (8) comprometimento com as pessoas; (9) foco no cidadão e na sociedade. (TCU, 2014, p.15)
} 
Ademais, essa estratégia de melhoria e aprendizagem gerencial visa aprimorar o desempenho institucional, focado na valorização e capacitação profissional, caracterizado por ações que otimizem processos e permitam o gerenciamento de projetos e de riscos, levando-se em consideração os resultados obtidos com os processos anteriores de Gestão da Qualidade Total (GQT), Gestão Contemporânea (GECON) e Reengenharia (RGA).

\section{APRESENTAÇÃO E DISCUSSÃO DOS RESULTADOS}

Do questionário aplicado (EloGroup/BPM), observa-se que a amostra se caracteriza por respondentes formados em administração, pela Escola Naval (43\%) e ciências contábeis (29\%). Com faixa etária acima dos 40 anos e com tempo médio de serviço de 22 anos, sendo 7 anos como gestores efetivos e outros 3 anos e meio na área de controle interno da instituição, releva destaque o fato de que, especificamente na área de gestão de risco, a média de atuação pode ser considerada baixa, em torno de 9 meses, o que indicia certa fragilidade à memória institucionalizada das práticas de gestão de risco em reflexão.

Da parte específica do questionário, mensurada pela escala Likert de 5 pontos e segregada para análise nas componentes (i) capacidade e estruturação da gestão de risco, (ii) monitoramento e revisão da gestão de risco e (iii) governança, riscos e controle, o quadro apresenta seus resultados de média, desvio padrão e coeficiente de variação:

Tabela $\mathrm{n}^{\circ}$ 1: Análise descritiva do modelo EloGroup/BPM

\begin{tabular}{|l|c|c|c|}
\hline \multicolumn{1}{|c|}{ Elementos da Gestão de Risco } & Média & $\begin{array}{c}\text { Desvio } \\
\text { Padrão }\end{array}$ & $\begin{array}{c}\text { Coeficiente de } \\
\text { Variação }\end{array}$ \\
\hline Capacidade e Estruturação & 3,35 & 1,42 & $42,4 \%$ \\
\hline Monitoramento e Revisão & 3,31 & 1,38 & $41,5 \%$ \\
\hline Governança, Riscos e Controle & 4,14 & 0,58 & $14,0 \%$ \\
\hline
\end{tabular}

Fonte: dados de pesquisa

A média 3,35 obtida pela componente "capacidade e estruturação da gestão de riscos”, apesar do desvio padrão e o coeficiente de variação apontarem significante dispersão de dados, das entrevistas foi possível preencher lacunas de informações, em especial:

a) $85 \%$ das organizações possuem controles internos baseados em gestão de riscos;

b) A própria estrutura organizacional estabelece instâncias de supervisão de controles internos de processos. Enquanto os Encarregados de Divisão supervisionam processos afetos às suas áreas, o Vice-Diretor, como agente fiscal, realiza a fiscalização rotineira das contas de gestão e, diretamente ligado ao Diretor, um assessor de controle e capacitação exerce a supervisão da gestão e controles internos; e

c) O Conselho de Gestão, presidido pelo Diretor, aprecia as contas de gestão e aponta as devidas recomendações, integrando os agentes responsáveis pela governança, gestão de riscos e pelos controles.

Quanto à componente “monitoramento e revisão da gestão de riscos”, com valor médio de 3,31 pontos e também valores relevantes de dispersão de dados, apontados pelos 1,38 pontos de desvio padrão e 41,5\% de coeficiente de variação, também puderam ser atenuados pela parte qualitativa do estudo, com destaque: 
a) $70 \%$ das organizações participam de premiações externas de "Excelência de Gestão”, propiciando a troca de experiências e o benchmarking de boas práticas, reforçando a busca contínua pela melhoria das atividades realizadas; e

b) Percepciona-se que o Programa Netuno é fundamental para a sistematização de práticas relacionadas à gestão de riscos, aos controles internos e à governança, desenvolvendo tal mentalidade em todos os integrantes da organização, ou seja, observa-se a preocupação dos gestores em se capacitar e praticar as orientações existentes.

No que tange à componente "governança, riscos e controle”, os dados indiciam uma forte aderência das organizações do SAbM ao conceito de governança corporativa, seus princípios e estruturas basilares de gestão de risco e controle interno. A pontuação média de 4,14 aponta para um estágio de maturidade entre “Gerenciado” e “Otimizado” na percepção de seus profissionais, reforçado por um desvio padrão de 0,58 e um coeficiente de variação de apenas $14 \%$, ou seja, indicando pouco dispersão dos dados obtidos.

Quadro nº 4: Análise descritiva do estágio de maturidade da Gestão de Riscos

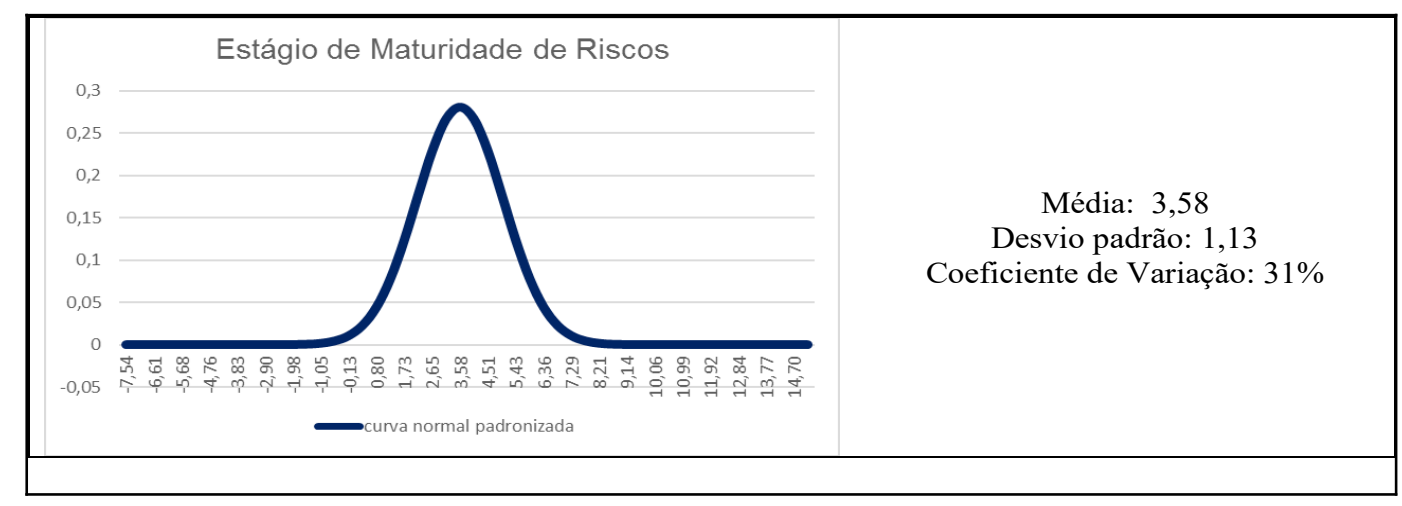

Fonte: dados da pesquisa

Por conseguinte, com o coeficiente médio de maturidade de 3,58 pontos, com desvio padrão de 1,13 e o coeficiente de variação de 31\%, constata-se que as organizações do SAbM se encontram no estágio “Definido” de maturidade em Gestão de Riscos.

Em crescente aprimoramento para uma abordagem mais corporativa, as organizações se adaptam e procuram influenciar seu ambiente, ampliando seu escopo de decisão para além de seus objetivos, buscando incorporar projetos que reforcem objetivos institucionais, dentro dos conceitos básicos de governança.

De fato, os dados permitem depreender que as estratégias e políticas foram devidamente implementadas e disseminadas, capacitando-as à abordagem corporativa da Gestão de Riscos, isto é, o SAbM caminha ao atendimento à Política de Gestão de Risco, atualmente em fase validação junto ao primeiro ciclo de revisão do Plano Estratégico da Marinha (2017-2019).

\section{CONSIDERAÇÕES FINAIS}

Neste momento se torna oportuno o retorno aos objetivos para a investigação, confrontando-os com os resultados apresentados, a fim de dar sustentabilidade à resposta da pergunta de partida: Como a Gestão de Risco tem contribuído para o processo de tomada de decisão nas $\mathrm{OM}$ da $\mathrm{MB}$ ?

Independente da missão da organização militar, a prestação de serviços e o alcance dos seus objetivos estão cercados por incertezas que podem gerar ameaças ao sucesso ou oportunidades de melhoria, e devem ser gerenciadas de forma estruturada, ou seja, a gestão 
de riscos é essencial para o sucesso no cumprimento da missão de qualquer organização e pode ajudar a melhorar a eficiência, eficácia e efetividade das atividades realizadas.

A análise documental permitiu também descrever a estruturação da gestão de riscos na $\mathrm{MB}$, que atribui responsabilidades a diversas OM para execução das tarefas e define critérios para análises dos riscos, de acordo com o nível da organização, dentro do organograma da Força. O estudo realizado revelou ainda o uso de informações sobre riscos na tomada de decisão dessas OM, por meio do Plano de Gerenciamento de Riscos, assim como o fortalecimento do controle interno das unidades, mormente, através da atuação efetiva do Conselho de Gestão.

Sob esse aspecto, o Programa Netuno é fundamental para a sistematização de práticas relacionadas à gestão de riscos, aos controles internos e à governança, com foco na gestão com excelência, permitindo que a organização não olhe somente para o passado, comparando planejamento com execução de metas, mas também busque o caminho certo, em direção à consecução dos seus objetivos estratégicos.

Deste modo, buscou-se também refletir sobre a capacidade de adaptação do Estado ao seu dinâmico contexto de atuação. Nesse momento, amparados por princípios e diretrizes pré-definidas na recém instituída Política de Governança Pública (Decreto nº 9.203/2017), inaugura-se mais uma fase de coordenação da atividade estatal, buscando manter a flexibilidade para as correções de rumos e prioridades que se farão necessárias, direcionadas para objetivos alinhados aos interesses da sociedade.

\section{REFERÊNCIAS BIBLIOGRÁFICAS}

[1] BRASIL. Casa Civil da Presidência da República. Guia da Política de Governança Pública. Brasília: Casa Civil, Subchefia de Análise e Acompanhamento de Políticas Governamentais, 2018.

[2] . Instrução Normativa Conjunta CGU/MP Nº 001, de 10 de maio de 2016. Diário Oficial da União, Poder Executivo, Brasília, DF, 2016.

[3] —. Marinha do Brasil. ARMADAINST-32-1: Instruções para Implementação da Política de Gestão de Riscos da Marinha do Brasil. Brasília, DF, 2017.

[4] . EMA-130: Manual de Visita, Inspeções e Reuniões Funcionais da Marinha Listas de Verificação. v. 2, Brasília, DF, 2006. 2011. . EMA-134: Manual de Gestão Administrativa da Marinha. v. 2, Brasília, DF, . SGM-107: Normas Gerais de Administração. v. 6. Brasília, DF, 2015. . SGM-601: Normas sobre Auditoria, Análise, Prestação e Tomada de Contas na Marinha. v. 5. Brasília, DF, 2014. . Tribunal de Contas da União. Revista do Tribunal de Contas da União, v.1, nº 135. Brasília: TCU, 2016.

Dez passos para a boa governança. Brasília: TCU, Secretaria de Planejamento, Governança e Gestão, 2014.

[10] CAMÕES, P. J. Design de investigação. In SILVESTRE, H. C.; ARAÚJO, J. F. (Coord.). Metodologia para a investigação social, p. 103-119. Lisboa: Escolar Editora, 2012. 
[11] COSO - Committee of Sponsoring Organizations of the Treadway Commission. Controle Interno: Estrutura Integrada. Price Watherhouse Coopers e Instituto dos Auditores Internos do Brasil (trad.), São Paulo, 2013.

[12] _ Gerenciamento de Riscos Corporativos: Estrutura Integrada. (COSO GRC, 2004). Price Watherhouse Coopers e Instituto dos Auditores Internos do Brasil (trad.), São Paulo, 2007.

[13] ELOGROUP, Consultoria. Maturidade de Business Process Management (BPM), 2015. Disponível: http://elogroup.com.br/conhecimento/insights/maturidade-de-bpm.

[14] FREITAS, A. M. R.; OLIVEIRA, A. R.; EMMENDOERFER, M. L. CUNHA, N. R. S. Institucionalização da política de desenvolvimento de pessoas em Instituições Federais de Ensino em Minas Gerais. Revista Gestão Universitária na América Latina, 5 (3), 108-131, 2012.

[15] HARRISON, J. J. H. Corporate governance in the NHS - an assesment of boardroom practice. Corporate Governance, 6 (3), p. 140-150, 1998.

[16] IIA - Institute of Internal Auditors. As Três Linhas de Defesa no Gerenciamento Eficaz de Riscos e Controles: Declarações de Posicionamento do IIA. Janeiro, 2013.

[17] INTOSAI - International Organization of Supreme Audit Institutions. Reporting Standards in Government Auditing (ISSAI 400). Vienna, 2001.

[18] MACHADO, N. GBRSP - Gestão baseada em resultado no setor público: uma abordagem didática para implementação em prefeituras, câmaras municipais, autarquias, fundações e unidades organizacionais. São Paulo, 2012.

[19] MEIRELLES, H. M. Direito Administrativo Brasileiro, 42 a ed. São Paulo: Malheiros, 2016.

[20] MINTZBERG, H.; AHLSTRAND, B.; LAMPEL, J. Strategy safari: a guide tour through the wilds of strategic management. New York: Free Press, 1998.

[21] MOREIRA. C. Teorias e práticas de investigação. Lisboa: Instituto Superior de Ciências Sociais e Políticas, 2007.

[22] PORTER, M. E. What is strategy? Harvard Business Review,74(6), p. 61-78, 1996.

[23] RODRIGUES, M. A. V.; TAVARES, A. F.; ARAÚJO, J. F. Municipal servisse delivery: The role of transaction costs in the choice between alternative governance mechanisms. Local Government Studies, 38 (5), p. 615-638, 2012.

[24] YIN, R. K. Estudo de caso: planejamento e métodos. 5a ed. THORELL, A. (trad.). Porto Alegre: Bookman, 2015. 